\title{
Mindfulness-Based Relapse Prevention to Reduce High Risk Behaviors of People Addicted to Methamphetamine
}

\author{
Farideh Hamidi (Di) ${ }^{1,}$ and Salimeh Kheiran ${ }^{2}$ \\ ${ }^{1}$ Department of Educational Sciences, Shahid Rajaee Teacher Training University, Tehran, IR Iran \\ ${ }^{2}$ Department of Psychology, Islamic Azad University, Tehran Branch, Tehran, IR Iran \\ "Corresponding author: Department of Educational Sciences, Shahid Rajaee Teacher Training University, Tehran, IR Iran. Emails: fhamidi@sru.ac.ir; hamidi.f@gmail.com
}

Received 2019 April 26; Revised 2019 May 25; Accepted 2019 June 01.

\begin{abstract}
Background: The cognitive behavior model of addiction forms the basis for relapse prevention, an intervention that attempts to describe, understand, prevent, and manage relapse in individuals who have received, or are receiving, treatment for substance use disorders.

Objectives: The aim of this study was to investigate the effectiveness of Mindfulness-Based Relapse Prevention (MBRP) educational interventions to reduce some high-risk behaviors like aggression and craving in people with methamphetamine dependence in Kashan (a city of IR Iran).

Patient and Methods: The present research was a quasi-experimental study with pretest- posttest and a control group. Samples concluded 30 males and females with diagnosis of methamphetamine dependence based on DSM-5 criteria and randomly divided into two groups of experimental and control groups each with 15 subjects. Two groups completed the Craving Beliefs questionnaire (CBQ) and Eysenck and Wilson's Aggression questionnaire. The experimental group received 8 sessions of 1.5 hours, under the preventive training of MBRP and after the completion of the intervention sessions, the variables in the post-test stage were re-measured in two groups.

Results: Data was analyzed by descriptive statistics and analysis of covariance. Results showed a significant difference between the experimental and control groups in two variables $(\mathrm{P}<0.01)$. MBRP intervention decrease craving and aggression in clients as hard risk behaviors of methamphetamine-dependent individuals. Eta coefficients were $27 \%$ for craving and $53 \%$ for aggression.

Conclusions: Research indicated mindfulness training intervention as MBRP was effective for addicts to amphetamines. This method of prevention helped them increase their ability of coping with temptation and high-risk behaviors as the symptoms of the abortion.
\end{abstract}

Keywords: Mindfulness, Health Risk Behaviors, Methamphetamine, Addiction

\section{Background}

Drug abuse in many people begins at high school, so one of the major important ways to reduce the consumption of drugs is controlling it in adolescence (1). For people working with adolescents, the most important danger that threatens this group is that they are responding to repeated misconduct in inappropriate situations such as feeling insecure, pressure, psychological distress, feelings of humiliation, conflict with parents, and drug addiction (2). Symptoms of substance dependence are a set of physiologic and behavioral-cognitive symptoms that suggest that the person continues to use it despite drug-related abnormalities $(3,4)$. In such cases, there is a pattern of abuse that usually results in tolerance, deprivation, and compulsory behavior for consumption. According to this definition, drug abuse leads to the destruction of mental or physical functions, whereas dependence takes place when an individual has forced and uncontrollable consumption, and manifests withdrawal symptoms in case of non-use (5).

In recent years, the abuse pattern of Iranians has changed drastically, and drug abusers, especially the young generation look for experiencing new drugs such as methamphetamine, crack, and heroin. Methamphetamine, whose crystal form is known as Crystal in Iran, is one of the most abused cases (6). Most addicts tend to change the drug-dependent lifestyle, yet the many problems in the treatment period lead to relapse and discontinuation of treatment. Addiction has been introduced as a reversible acute problem (7). Addiction is a chronic, recurrent and complex disorder, which continues with disastrous negative consequences. Self-control 
cognitive system increases the individual's readiness to avoid temptation to addiction, as a result of the success in reducing drug use $(8,9)$. Lan et al. (10) concluded that the positive effect of mindfulness-based cognitive-behavioral therapy in the treatment of smartphone addiction in Chinese students was effective. Daley and Marlatt (11) have pointed that three out of four people who quitted had a relapse within a year after completion of the treatment. Moreover, among addicting amphetamine drugs, methamphetamine is the strongest. They have higher risk of dependence and mental health problems (12). These substances also have high psychosis (13), and are connected to cognitive problems such as attention loss, distraction (14). Continuity factors for addictional behaviors include craving and a reliever in emotional regulation (15).

Wright et al. (16) stated that craving for abuse has cognitive roots in inadequate belief in the need for drugs. It seems that craving for a drug is controlled by cognitive, emotional, automatic or non-automatic processes, so that theories of craving generally emphasize that urges in people are associated with the activation of emotions and the motives for the search for drugs.

The greatest threat to a recovering patient is the underlying cause of the recurrence of craving, and if not carefully controlled, it is very confusing for the person and may result in re-abuse of the substance. The Tenth Revision of the International Classification of Diseases and Health Problems (ICD-10) defines the dependence syndrome as being a cluster of physiological, behavioral, and cognitive phenomena in which the use of a substance or a class of substances takes on a much higher priority for a given individual than other behaviors that once had greater value (17). The craving is affected by the triggering factors and the high-risk situation, the stimulants lead to the thought of drug abuse, which in turn ends in craving and ultimately abuse. In the treatment of the prevention of the addiction relapse, negative and positive emotional states experiences, desire and craving are among the most important risk factors for relapse (18). Mindfulness enhances awareness of thinking in such a way that it regulates emotions and improves academic achievement (19). High emotional disturbances in adolescence can lead to high risk behaviors (20).

Tapper (21) reviewed 30 experimental studies with a variety of mental concentration methods. It was concluded that attitudes and addiction to cigarettes and alcohol have a significant effect on the types of risk behaviors. Recently, cognitive-behavioral therapy promotes method and strategies based on mindfulness which effects different high-risk behaviors and psychosis (22). Some of these approaches showed improvements in social problems, aggressive be- havior, attention problems and sleep quality on school nights (23). Perry (24) in a qualitative analysis about addiction recovery based on mindfulness concluded that many participants consider mindfulness exercises to be very effective in controlling relaxation and their impulsive behaviors. The highest impact of these exercises was in their relationships, trust and mutual respect.

Some researchers believe that the use of mindfulness method due to latent mechanisms in it such as accpetence, increased awareness, desensitization, momentary presence, observation without judgment, confrontation and release, combined with traditional cognitive behavioral therapies, given the effect of these processes, can increase the efficacy of the treatment and reduce the recurrence of drug abuse while reducing the symptoms and consequences of relapse drug abuse (25). Moreover, effectiveness of mindfulness intervention in reducing depression and anxiety showed desire to survive and coping with life's problems (26).

According to the literature and the studies conducted in this field, one can conclude that MBRP prevention interventions have not been studied on psychological aspects related to drug dependence such as craving, emotional regulation and aggression. Thus, the present study investigates the question of whether MBRP intervention affects craving, emotional regulation and aggression in people dependent on methamphetamine.

\section{Objectives}

The study aimed to reduce high risk behaviors such as aggression and craving in addicted people to methamphetamine, based on mindfulness relapse prevention.

\section{Patients and Methods}

The present study was a pretest-posttest with control group. The population of this study included all patients abusing methamphetamine who referred to 5 short-term residence abandonment centers under the supervision of Welfare Organization of Isfahan and 84 Drug Addiction Treatment Centers of Torabi under the supervision of Kashan University of Medical Sciences in Kashan (a city of IR Iran) in 2016. Thirty males and females with diagnosis of methamphetamine dependence were selected based on DSM-5 criteria. After obtaining the inclusion criteria and consent of the participants in the treatment sessions, they entered the research plan. Later on, male and female subjects in Short-Term Addiction Treatment Centers in Mehr-e Aghayan, Tolu-e Banovan Short-Term Addiction Treatment Center, and Keshmiri and Rahayi centers for 
methadone withdrawal in Kashan with high craving and high aggression and deficiency in regulating emotions were randomly divided into two groups of experimental and control groups each with 15 subjects.

\subsection{Instruments}

\subsubsection{Craving Beliefs Questionnaire}

This questionnaire is a self-assessment scale designed by Wright in 2003 to measure the craving to abuse drugs (27). The questionnaire has 20 items with a 1-7 scale (from totally disagree to totally agree). This test has a good validity and reliability, with its reliability using Cronbach's alpha coefficient reported to be $95 \%$. Moreover, its formal and content validity has been confirmed by the relevant faculty members and experts (28).

To examine the reliability, internal consistency coefficient using Cronbach's alpha (0.84) and split-half method $(0.81)$ were measured. The reliability of this scale was 0.77 using Cronbach's alpha.

\subsubsection{Eysenck and Wilson's Aggression Questionnaire}

Eysenck and Wilson's Aggression Questionnaire was developed by Eysneck and Wilson in 1975, which consists of 30 three-option questions, with 20 items having positive and 10 having negative answers (29). The subjects respond to the questions with "yes", "no" and "no answer". The validity of this scale is content validity. In determining the content validity, all the questions are examined. Content validity means that questions should include different aspects of aggression. The validity of this test was determined by Eysneck himself. Thus, it was prepared for doing clinical work and conducted on 120000 women, men, children, adults, normal, nervous, psychiatric patients, criminals and, 2000 pairs of twins. Furthermore, it was conducted on many adults and children involved in the preparation of the primary patterns of the norms. The Cronbach's alpha coefficient obtained in the study was 0.68 .

\subsection{The Content of Treatment Sessions}

By combining research on the prevention of relapse as a drug dependence treatment with existing techniques based on the mindfulness (30-32), a new cognitive intervention was suggested for drug abuse called MBRP. Thus, MBRP educational intervention is a new behavioral therapy mixing traditional prevention techniques with meditating mindfulness to treat drug abuse disorders. This combination is referred to as the third wave of behavioral therapy. The Marlatt treatment plan for MBRP is provided in Table 1 , so this section briefly refers to the titles and general structure of the sessions (33).

\begin{tabular}{|c|c|}
\hline Session & Details \\
\hline First session & $\begin{array}{l}\text { Welcoming patients, introducing members, getting } \\
\text { consent from patients, introducing this disorder and } \\
\text { introducing treatment, raising awareness and getting } \\
\text { feedback from the session }\end{array}$ \\
\hline Second session & Body scan meditation 45 minutes, dignity paper \\
\hline Third session & $\begin{array}{l}\text { Body scan meditation } 45 \text { minutes, mindfulness paper, } \\
\text { sitting meditation for } 15 \text { minutes }\end{array}$ \\
\hline Fourth session & Practicing seeing and hearing \\
\hline Fifth meeting & Sitting mediation, STOP Technique \\
\hline Sixth session & $\begin{array}{l}\text { Body scanning meditation } 45 \text { minutes, kindness paper, } \\
\text { interpersonal meditation }\end{array}$ \\
\hline Seventh session & $\begin{array}{l}\text { Body scan meditation } 45 \text { minutes, the role of thoughts in } \\
\text { relapse, aerobic procedures, deep breathing, } \\
\text { concentration }\end{array}$ \\
\hline Eighth session & $\begin{array}{l}\text { Body scan meditation scan } 45 \text { minutes, reviewing } \\
\text { treatment sessions }\end{array}$ \\
\hline
\end{tabular}

\subsection{Procedure}

Thirty individuals selected prior to the implementation of the study were tested for detoxification by Thin Layer Chromatography (TLC) and then randomly assigned to control and experimental groups, and both groups received methadone treatment. Research variables in pretest stage were measured in two groups. MBRP intervention was conducted on the experimental group for 2 months in form of 8 sessions of 1.5 hours, with the control group receiving no intervention. After finishing the sessions, all subjects of the two groups completed the resiliency, tolerance of distress and craving questionnaires.

\subsection{Ethical Considerations}

Questionnaires were given to the samples anonymously to not show their identity. The participants were assured that the data from the questionnaire would be used in line with the objectives and hypotheses of the present study. Responding to the questionnaires was completely voluntary and free, so that people would quit if they did not want to participate in the research.

In order to comply with the principles of ethics, after completing treatment sessions, people who were in the control group received several group sessions.

\section{Results}

As pre-test post-test was used in this study. In line with this MBRP in two levels of control and experiment, dependent variables include craving and aggression in metaamphetamine-dependent patients, and the control variable of pre-test scores in the dependent variable were age and gender. 
Descriptive statistics (mean, standard deviation, so on) and inferential statistics of co-variance analysis with its presumptions were used in this study.

Kolmogorov-Smirnov test shows the normal distribution of scores. The significance level of all variables is greater than 0.01 , so the distribution of the scores is normal.

To examine the regression slope homogeneity, we computed the interaction between the independent variable and the integral variable. Results showed that the F value for all three variables was significant (Sig < 0.01). Thus, the presumption of regression slope homogeneity is not observed. Thus, data is examined more carefully.

The results of covariance analysis for the study of MBRP educational intervention on craving deficits are shown in Table 2. F value between the experimental and control groups with constant pre-test was 10.10 and its significance level was 0.004 , so the statistical hypothesis was accepted and it can be concluded that MBRP intervention reduces craving. Moreover, the effect of the intervention on craving was calculated at $27 \%$ according to the obtained Eta coefficients.

The results of covariance analysis for the study of MBRP educational intervention on aggression deficits are shown in Table 3. F value between the experimental and control groups with constant pre-test was 30.77 and its significance level was 0.01 , so the statistical hypothesis was accepted with $99 \%$ level of confidence and it can be concluded that MBRP intervention affects aggression. Moreover, the effect of the intervention on aggression was calculated at 53\% according to the obtained Eta coefficients.

\section{Discussion}

MBRP interventions have a positive effect on craving reduction in methamphetamine-dependent individuals. As the results of the tables showed, MBRP educational intervention had a significant effect on craving reduction. These findings are consistent with previous findings (34). MBRP has effectively increased the effectiveness of drug dependence treatment in improving the mental health of patients. Mindfulness-based intervention can increase the coping ability of the patient to cope with the craving and the symptoms of withdrawal. Furthermore, this treatment as one of the main methods of admission strategies makes the patient, instead of challenging and avoiding uncomfortable thoughts and emotions caused by quitting or use of substances to relieve them, establishing a different communication style without reaction and a new processing method admitting information, thoughts and feelings of distress without judging and evaluating them and get along with desensitization. Some part of these changes can be due to the practical mechanisms proposed in the mindfulness method, such as confrontation, acceptance, relaxation, desensitization, and change in relation to thought $(8,25)$. Craving is the strongest predictor of relapse among other predictors (even comorbidities with disorders such as anxiety and depression), and mindfulness can reduce the negative effects of craving well (35). Mindfulness training can increase craving control and reduce the stress associated with abuse (36).

Many authors have stated that mindfulness activity exercises can result in changes in thinking patterns or attitudes about one's thoughts. For instance, Kabat-Zinn recommended that observation without judgment of the pain and thoughts associated with drug abuse might end in an understanding that these are mere thoughts and do not represent reality or truth, and should not necessarily lead to escape or avoidance $(37,38)$. Mindfulness make addicts be aware of their thoughts and guides the addicted persons' thoughts to other dimensions, such as breathing, walking with the presence of the mind and the sounds of the environment, and thereby reducing craving. Teasdale (35) calls this phenomenon metacognitive insight. Exercises, interpersonal meditation of the third session, increasing awareness during daily activities in all sessions, and deep breathing exercises in the third session could prevent the craving.

MBRP interventions have a positive effect on reducing the aggression of methamphetamine-dependent people. As the results in the table show, MBRP had a significant effect on the reduction of aggression. Increasing studies suggest its usefulness and admit the effectiveness of mindfulness and its positive effect on behavioral abnormalities such as aggression (36).

In mindfulness, attention to the body and breathing is practiced, and we are aware of the various senses we experience in our bodies and even our breathing. We also find that when our body is warmed up in anger, or in the state of fear, our heart rate increases, and our breathing changes and becomes short and fast. By practicing yoga exercises, we increase focus on the body and this knowledge provides the ground for control next. In teaching control, the person learns to eliminate any judgment that leads to anger and aggression from his mind in him and focus deeply on the present and applies it to his/her daily behaviors. In order to increase attention control, the person learns to practice this in his/ her life alternately in the work involved, until he reaches a point that is fully attentive to time and place.

The important effect that comprehensive attention has on anger and aggression is that, as a coping strategy, it separates anger from its painful state and works in a flexible and realistic manner in dealing with problems. 


\begin{tabular}{|c|c|c|c|c|c|c|}
\hline Change Source & Sum Squares & Df & $\mathbf{F}$ & Sig. & Eta Square & Df Error \\
\hline The craving pre-test (covariance effect) & 0.75 & 1 & 0.75 & 0.002 & 0.96 & 0.001 \\
\hline Group & 4214.71 & 1 & 4214.71 & 10.10 & 0.004 & 0.27 \\
\hline Error & 141248 & 30 & & & & \\
\hline Total & 15535.86 & 29 & & & & \\
\hline
\end{tabular}

\begin{tabular}{|c|c|c|c|c|c|c|}
\hline Change Source & Sum Squares & Df & $\mathbf{F}$ & Sig. & Eta Square & Df Error \\
\hline The craving pre-test (covariance effect) & 2145.74 & 1 & 35.96 & 0.001 & 0.57 & 0.001 \\
\hline Group & 4318.66 & 1 & 30.77 & 0.001 & 0.53 & 0.27 \\
\hline Error & 35099 & 30 & & & & \\
\hline Total & 5708.30 & 29 & & & & \\
\hline
\end{tabular}

\subsection{Conclusions}

The goal of this study was to reduce high risk behaviors of people addicted to methamphetamine based on MBRP. In the present study, aggression and craving in addicted people as high-risk behaviors was focused upon. Given the effectiveness of mindfulness training in prevention of the relapse of methamphetamine abuse, it is recommended that the use of this method and psychological training workshops be held on this. Conducting continuous mindfulness techniques has a positive impact on reducing drug addiction. Patients learn to avoid high-risk situations and behaviors by mastering skills such as denial of admission, aggression and temptation control, effective communication and decisive behaviors. Learning cognitive techniques also helps patients to turn their attention away from stimulating thoughts into narcotics in the short term, and in the long run, they are challenged by these thoughts to prevent recurrence.

Moreover, given the cultural misconceptions among the people concerning the use of methamphetamine to reduce weight and fitness, especially among women, training classes can be held in this regard. Thus, mindfulness practice improved patients' insight and their selfawareness to use effective coping styles in the initial stage of a negative emotional state.

Future research should support the full execution of this program over an extended period with a number of populations to ascertain the program's efficacy. Among the limitations of the study, we can cite no follow-up periods. Moreover, as the eight-session period is long, MBRP intervention, and absence of the group members affects the effectiveness of interventions. It is recommended that the treatment method used in this study should be based on other methamphetamine variables, such as depression re- duction, anxiety reduction, increased tolerance of distress, and so on.

\section{Acknowledgments}

This research was performed according to the cooperation of the Welfare Organization of Isfahan and Drug Addiction Treatment Centers of Torabi under the supervision of Kashan University of Medical Sciences. Gratitude to the center for their coordination.

\section{Footnotes}

Authors' Contribution: Study concept and design: Farideh Hamidi and Salimeh Kheiran. Acquisition of data and intervention: Salimeh Kheiran. Statistical analysis and interpretation: Farideh Hamidi and Salimeh Kheiran. Study supervision: Farideh Hamidi.

Conflict of Interests: Authors declare that they have no conflict of interest.

Ethical Considerations: All procedures performed in studies involving human participants were in accordance with the ethical standards of the institutional and/or national research and informed consent was obtained from all individual participants included in the study.

Funding/Support: There was no any financial support.

Patient Consent: Informed consent was obtained from all individual participants included in the study.

\section{References}

1. Krohn MD, Lizotte AJ, Perez CM. The interrelationship between substance use and precocious transitions to adult statuses. J Health Soc Behav. 1997;38(1):87-103. [PubMed: 9097510]. 
2. Pates R, Riley D. Interventions for amphetamine misuse. Oxford: WileyBlackwell; 2009.

3. Rhemtulla M, Fried EI, Aggen SH, Tuerlinckx F, Kendler KS, Borsboom D. Network analysis of substance abuse and dependence symptoms. Drug Alcohol Depend. 2016;161:230-7. doi: 10.1016/j.drugalcdep.2016.02.005. [PubMed: 26898186]. [PubMed Central: PMC4861635].

4. Clark SL, Gillespie NA, Adkins DE, Kendler KS, Neale MC. Psychometric modeling of abuse and dependence symptoms across six illicit substances indicates novel dimensions of misuse. Addict Behav. 2016;53:132-40. doi: 10.1016/j.addbeh.2015.10.015. [PubMed: 26517709]. [PubMed Central: PMC4679450].

5. Abou-Saleh MT. Substance use disorders: Recent advances in treatment and models of care. J Psychosom Res. 2006;61(3):305-10. doi: 10.1016/j.jpsychores.2006.06.013. [PubMed:16938506].

6. Sarrami H, Ghorbani M, Minooei M. Survey of four decades of addiction prevalence researches in Iran. Res Addict. 2013;7(26):29-52. eng.

7. Van den Brink W, Haasen C. Evidenced-based treatment of opioiddependent patients. Can J Psychiatry. 2006;51(10):635-46. doi: 10.1177/070674370605101003. [PubMed: 17052031]

8. Brewer J. Mindfulness training for addictions: Has neuroscience revealed a brain hack by which awareness subverts the addictive process? Curr Opin Psychol. 2019;28:198-203. doi: 10.1016/j.copsyc.2019.01.014. [PubMed:30785066].

9. Priddy SE, Howard MO, Hanley AW, Riquino MR, Friberg-Felsted K, Garland EL. Mindfulness meditation in the treatment of substance use disorders and preventing future relapse: Neurocognitive mechanisms and clinical implications. Subst Abuse Rehabil. 2018;9:10314. doi: 10.2147/SAR.S145201. [PubMed: 30532612]. [PubMed Central: PMC6247953].

10. Lan Y, Ding JE, Li W, Li J, Zhang Y, Liu M, et al. A pilot study of a group mindfulness-based cognitive-behavioral intervention for smartphone addiction among university students. J Behav Addict. 2018;7(4):1171-6. doi: 10.1556/2006.7.2018.103. [PubMed: 30418075]. [PubMed Central: PMC6376383]

11. Daley DC, Marlatt GA. Overcoming your alcohol or drug problem: Workbook: Effective recovery strategies. 2nd ed. USA: Oxford University Press; 2006. doi: 10.1093/med:psych/9780195307740.001.0001.

12. Topp L, Degenhardt L, Kaye S, Darke S. The emergence of potent forms of methamphetamine in Sydney, Australia: A case study of the IDRS as a strategic early warning system. Drug Alcohol Rev. 2002;21(4):3418. doi: 10.1080/0959523021000023199. [PubMed: 12537703].

13. McKetin R, McLaren J, Lubman DI, Hides L. The prevalence of psychotic symptoms among methamphetamine users. Addiction. 2006;101(10):1473-8. doi: 10.1111/j.1360-0443.2006.01496.x. [PubMed: 16968349].

14. Nordahl TE, Salo R, Possin K, Gibson DR, Flynn N, Leamon M, et al. Low $\mathrm{N}$-acetyl-aspartate and high choline in the anterior cingulum of recently abstinent methamphetamine-dependent subjects: A preliminary proton MRS study. Magnetic resonance spectroscopy. Psychiatry Res. 2002;116(1-2):43-52. [PubMed: 12426033].

15. Heyman GM. Received wisdom regarding the roles of craving and dopamine in addiction: A response to Lewis's critique of addiction: A disorder of choice. Perspect Psychol Sci. 2011;6(2):156-60. doi: 10.1177/1745691611400243. [PubMed: 26162133].

16. Wright FD, Beck AT, Newman CF, Liese BS. Cognitive therapy of substance abuse: theoretical rationale. NIDA Res Monogr. 1993;137:123-46. [PubMed: 8289917].

17. World Health Organization. The ICD-10 classification of mental and behavioral disorders: Clinical descriptions and diagnostic guidelines. World Health Organization; 2017.

18. Marlatt GA, Bowen S, Chawla N, Witkiewitz K. Mindfulness-based relapse prevention for substance abusers: Therapist training and therapeutic relationships. In: Hick S, Bien T, editors. Mindfulness and the therapeutic relationship. New York:: Guilford Press; 2008.

19. Broderick PC, Jennings PA. Mindfulness for adolescents: A promis- ing approach to supporting emotion regulation and preventing risky behavior. New Dir Youth Dev. 2012;2012(136):111-26. 11. doi 10.1002/yd.20042. [PubMed: 23359447].

20. MacPherson L, Reynolds EK, Daughters SB, Wang F, Cassidy J, Mayes LC, et al. Positive and negative reinforcement underlying risk behavior in early adolescents. Prev Sci. 2010;11(3):331-42. doi: 10.1007/s11121010-0172-7. [PubMed: 20309633]. [PubMed Central: PMC3137922].

21. Tapper K. Mindfulness and craving: Effects and mechanisms. Clin Psychol Rev. 2018;59:101-17. doi: 10.1016/j.cpr.2017.11.003. [PubMed: 29169665].

22. Langer AI, Schmidt C, Mayol R, Diaz M, Lecaros J, Krogh E, et al The effect of a mindfulness-based intervention in cognitive functions and psychological well-being applied as an early intervention in schizophrenia and high-risk mental state in a Chilean sample: Study protocol for a randomized controlled trial. Trials. 2017;18(1):233. doi: 10.1186/s13063-017-1967-7. [PubMed: 28545578]. [PubMed Central: PMC5445512].

23. Blake MJ, Snoep L, Raniti M, Schwartz O, Waloszek JM, Simmons JG, et al. A cognitive-behavioral and mindfulness-based group sleep intervention improves behavior problems in at-risk adolescents by improving perceived sleep quality. Behav Res Ther. 2017;99:147-56. doi: 10.1016/j.brat.2017.10.006. [PubMed: 29101843].

24. Perry MB. Perceptions of mindfulness: A qualitative analysis of group work in addiction recovery. R I Med J (2013). 2019;102(2):28-31. [PubMed: 30823697].

25. Breslin FC. An information-processing analysis of mindfulness: Implications for relapse prevention in the treatment of substance abuse. Clin Psychol Sci Prac. 2002;9(3):275-99. doi: 10.1093/clipsy.9.3.275.

26. Milani A, Nikmanesh Z, Farnam A. Effectiveness of mindfulness-based cognitive therapy (MBCT) in reducing aggression of individuals at the juvenile correction and rehabilitation center. Int J High Risk Behav Addict. 2013;2(3):126-31. doi: 10.5812/ijhrba.14818. [PubMed: 24971290]. [PubMed Central: PMC4070155].

27. Altınöz AE, Aslan S, Uğurlu M, Özdel K, Sargın AE, Türkçapar MH Measuring the beliefs on alcohol craving by using craving beliefs questionnaire: Preliminary results of its psychometric properties in a Turkish sample. J Subst Use. 2016;21(5):455-9. doi: 10.3109/14659891.2015.1056852.

28. Chang CW, Huang CW, Wu WH, Wang BE, Liu YL, Shen HC, et al. Psychometric properties of the Chinese craving beliefs questionnaire for heroin abusers in methadone treatment. BMC Psychiatry. 2011;11:39. doi: 10.1186/1471-244X-11-39. [PubMed: 21388523]. [PubMed Central: PMC3065399].

29. Jackson CJ, Francis LJ. Primary scale structure of the eysenck personality profiler (EPP). Cur Psychol. 2004;22(4):295-305. doi: 10.1007/s12144004-1035-9.

30. Segal ZV, Williams JM, Teasdale JD. Mindfulness based cognitive therapy for depression. Anew approach to preventing relapse. New York: Guilford Press; 2002.

31. Witkiewitz K, Marlatt GA, Walker D. Mindfulness-based relapse prevention for alcohol and substance use disorders.J Cognit Psychother 2005;19(3):211-28. doi:10.1891/jcop.2005.19.3.211.

32. Marlatt G, Gordon J. Relapse prevention: Maintenance strategies in the treatment of addictive behaviors. New York: Guilford; 1985.

33. Marlatt GA. Buddhist philosophy and the treatment of addictive behavior. Cognit Behav Prac. 2002;9(1):44-50. doi: 10.1016/s10777229(02)80039-6.

34. Rawlett K, Scrandis D. Mindfulness based programs implemented with at-risk adolescents. Open Nurs J. 2016;10:90-8. doi: 10.2174/187443460160101090. [PubMed: 27347259]. [PubMed Central: PMC4895061].

35. Teasdale JD. The relationship between cognition and emotion: The mind-in-place in mood disorders. In: Clark DM, Fairburn CG, editors. Science and practice of cognitive behavior 
therapy. 1. Oxford, England: Oxford University Press; 1997. doi: 10.1093/med:psych/9780192627254.003.0004.

36. Wupperman P, Marlatt GA, Cunningham A, Bowen S, Berking M, Mulvihill-Rivera N, et al. Mindfulness and modification therapy for behavioral dysregulation: Results from a pilot study targeting alcohol use and aggression in women. J Clin Psychol. 2012;68(1):50-66. doi: 10.1002/jclp.20830. [PubMed: 21932371].

37. Kabat-Zinn J. Mindfulness-based interventions in context: Past, present, and future. Clin Psychol Sci Prac. 2003;10(2):144-56. doi: 10.1093/clipsy.bpg016.

38. Kabat-Zinn J. Full catastrophe living: Using the wisdom of your body and mind to face stress, pain, and illness. New York: Delacorte; 1990. 